\title{
Laparoscopic repair of a bladder rupture in 2 foals.
}

Astrid B.M. Rijkenhuizen, Lutz Goehring und Daniëlle P. K. Lankveld

Tierärztliche Fakultät, Universität Utrecht

\begin{abstract}
Summary
The laparoscopic repair of a bladder rupture using an endoscopic automatic suturing device (Endostich ${ }^{\circledR}$ ) in two foals is described. The foals were positioned in dorsal recumbency. In both foals the tear was detected in the dorsocranial part of the bladder. The defect was closed in two layers of inverting continuous sutures. Successful repair seemed not limited by accessibility, whereas the bladder could be approached from all directions. Based on the described cases the laparoscopic approach of bladder ruptures seems to be a viable option to operate minimally invasive and has the advantage of a short reconvalesence period, although the experience is admittedly limited. The mean operating time (which includes preparation of the patient) is still longer then for conventional surgery.
\end{abstract}

Keywords: bladder rupture, laparoscopy

\section{Laparoskopischer Verschluss einer Harnblaseruptur bei 2 Fohlen.}

An zwei Fallbeispielen wird die laparoskopische Korrektur einer Blasenruptur unter Verwendung eines endoskopisch eingesetzten Nahtapparats (Endostich ${ }^{\circledR}$ ) beschrieben. Nach Lagerung der Fohlen in Rückenlage war die Ruptur in der dorsokranialen Blasenwand laparoskopisch zugänglich. Der Defekt wurde in zwei Schichten einstülpend und fortlaufend verschlossen. Die Blase war rundum von allen Seiten gut anzugegehen und das Vernähen der Blasenwunde war durch den eingeschränkten Zugang nicht behindert. Aufgrund dieser beiden Fallbeschreibungen kann die Blasenruptur des Fohlens als brauchbare und nützliche Anwendung der chirurgischen Laparoskopie angesehen werden, die sich auch durch eine sehr kurze Rekonvaleszenz auszeichnet. Allerdings ist die Erfahrung mit dieser Methode noch beschränkt.

Schlüsselwörter: Harnblasenruptur, Laparoskopie, Chirurgie, minimalinvasiv

\section{Introduction}

The number and application of laparoscopic surgical procedures in general veterinary surgery are gradually increasing. The advantages are apparent. One of those applications is the repair of ruptured bladders in foals, which undoubtedly without surgical intervention is a life-threatening event. Surgical correction is indicated as soon as possible after the diagnosis, and after correction of typical electrolyte dysbalances. Conventional surgical methods are certainly appropriate in treating the condition; however, a reasonably large ventral midline incision is necessary for an uninhibited approach. The bladder defect is usually closed in two layers of inverting continuous sutures (Lillich and DeBowes 1999). The laparoscopic technique offers the opportunity to increase the approachability of the defect by visualising the bladder. It has been proven an effective tool for the diagnosis and treatment of bladder lacerations in human patients (Tay et al 1995, Poffenberger 1996, Appeltans et al 1998, Cottam et al 2001). The correction of a ruptured bladder by laparoscopic technique in a 90 day old foal has been described (Edwards et al 1996). The rupture was closed with staples; however, these staples were considered responsible to induce the formation of calculi 10 months later. This paper describes the laparoscopic repair of a bladder ruptured with the assistance of the Endostich $^{\circledR}$ and Polysorb ${ }^{\circledR}$ in 2 foals.

\section{Case details}

Case 1

Clinical findings

A 6 day old Trakehner filly was admitted to the Department of Equine Sciences with a suspected bladder ruptured and uroperitoneum. According to the owners micturition had been seen postpartum, and appeared normal.

The foal was able to walk into the clinic, and the foal did not show signs of colic. However, the abdomen was distended and the foal was lethargic. The foal was tachycardic (132 beats/minute) and tachypneic (72 breaths/minute). There was no fever, and the mucous membranes were mildly congested. The abdomen was positive on an undulation test, and intestinal sounds were absent. A transabdominal ultrasound examination showed a large amount of free fluid, combined with a small, contracted bladder, which could be visualized in the caudal abdomen. Clinical-pathological analysis substantiated a suspected rupture of the bladder (Fenger 1998): there was a profound hyponatremia $(115 \mathrm{mmol} / \mathrm{L})$, hypochloremia (86 mmol/L) and hyperkalemia $(6.8 \mathrm{mmol} / \mathrm{L})$. Azotemia was profound with creatinine measured at 464 (mol/L and blood urea nitrogen at $19.3 \mathrm{mmol} / \mathrm{L}$. An abdominocentesis was performed and very transparent fluid was collected with a creatinine concentration of 1550 (mol/L. 
A jugular vein catheter was placed and a hypertonic saline infusion $(\mathrm{NaCl} 3 \%, 1 \mathrm{~L})$ at $6 \mathrm{ml} / \mathrm{kg} /$ hour was administered. Simultaneously, the abdomen was drained. Surgical, laparoscopic intervention was initiated at the moment the foal's potassium concentration had normalised ( $<5.5 \mathrm{mmol} / \mathrm{L}$ ). Additionally and prior to surgery the foal received sodium ampicillin 1 intravenously $(20 \mathrm{mg} / \mathrm{kg}$ BWT).

\section{Surgical treatment}

Laparoscopy was performed under general anaesthesia using the following protocol. Prior to induction nalbuphine ${ }^{\circledR 2}(0.1$ $\mathrm{mg} / \mathrm{kg}$ BWT, iv) was administered. Anaesthesia was induced with propofol ${ }^{\circledR 3}(2 \mathrm{mg} / \mathrm{kg}$ BWT, iv). After induction the foal was intubated endotracheally and connected to a semi-closed anaesthetic circle system. Anaesthesia was maintained by isoflurane ${ }^{\circledR 4}$ in $100 \%$ oxygen. The foal was mechanically ventilated. Anaesthesia was monitored by recording electrocardiography (ECG), capnography, pulse-oximetry, arterial blood pressure, arterial $\mathrm{pH}, \mathrm{PaO}_{2}$ and $\mathrm{PaCO}_{2}$ (arterial oxygen and carbondioxide partial pressure, respectively) and physiological parameters. Saline solution was infused intravenously throughout anaesthesia at $10 \mathrm{ml} / \mathrm{kg} / \mathrm{hour}$.

Therapeutic laparoscopy was carried out in dorsal recumbency and the foal was routinely prepared for aseptic surgery. Laparoscopy was accomplished by the use of 3 portal sites: one for the laparoscope ${ }^{5}$ (diameter $10 \mathrm{~mm}$, length 57 $\mathrm{cm}$, angle either straight forward $0^{\circ}$ or $30^{\circ}$ ) and 2 for the instruments (12 $\mathrm{mm}$ and $5 \mathrm{~mm}$ ). Decompression and drainage of the uroperitoneum was performed through a $5 \mathrm{~mm}$ tro-

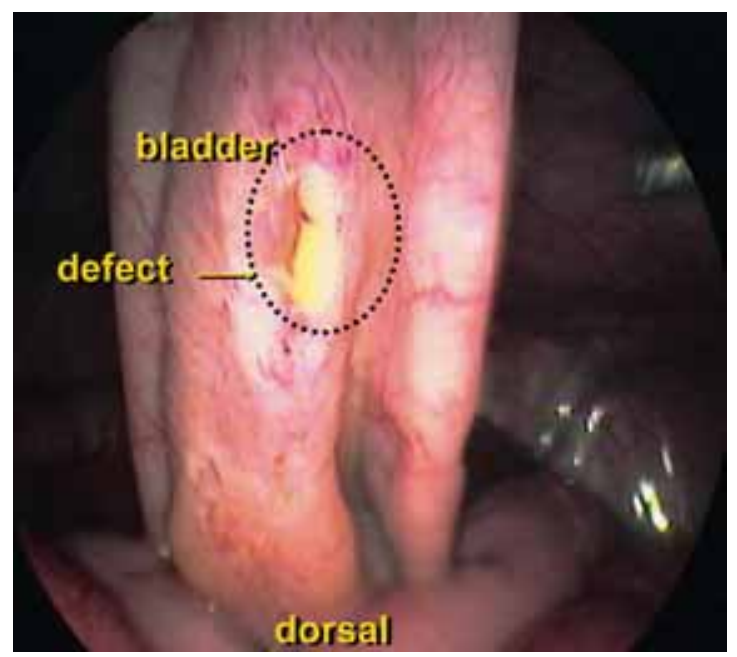

Fig 1a Case 1: Laparoscopic view of the bladder attached to the ventral abdominal wall. The defect is dorsocranially.

Fall 1: Laparoskopische Ansicht dermit der dorsalen Bauchwand verklebten Blase. Der Defekt liegt dorsocranial.

car placed $3 \mathrm{~cm}$ cranial and to the right side of the umbilicus to avoid damage of the umbilical structures. A $1.5 \mathrm{~cm}$ skin incision was made and a smaller incision through the external rectus sheath. The sheath was grasped with forceps on both sides and lifted up, while the remaining abdominal wall was perforated blind with the $5 \mathrm{~mm}$ trocar ${ }^{3}$ and the trocar sheath was placed. After removal of the urine the abdomen was distended with $\mathrm{CO}_{2}$ until a pressure of $10 \mathrm{mmHg}$ was reached using a carbon dioxide $\left(\mathrm{CO}_{2}\right)$-insufflator ${ }^{5}$ (flowrate 7-8 L/min). After decompression, the $5 \mathrm{~mm}$ trocar was replaced by a $10 \mathrm{~mm}$ trocar sheath for the portal of the laparoscope with the use of a sharp safety shielded obturator 6 . The abdomen was explored systematically, and the bladder and umbilical structures were identified. A fresh longitudinal tear of $3 \mathrm{~cm}$ was visible on the dorsocranial aspect of the bladder (Fig $1 \mathrm{a}$ and $1 \mathrm{~b}$ ). The bladder was attached to the abdominal wall by the urachus. Under laparoscopic view (to avoid visceral injury) two instrumental portals for the $5 \mathrm{~mm}^{6}$ and $12 \mathrm{~mm}^{7}$ trocar sheaths were made $4 \mathrm{~cm}$ lateral and caudal on both sides of the umbilicus. The foal was positioned in Trendelenburg position $\left(30^{\circ}\right)$ for further exposure of the bladder by letting the intestine move cranially. The intestine stayed in position cranially and the foal was repositioned horizontally after about 15 minutes. The edges of the tear appeared viable and there was no need for debridement. The tear was sutured laparoscopically with a $36 \mathrm{~cm}$ long, $10 \mathrm{~mm}$ endoscopic automatic suture device $\left(10 \mathrm{~mm}\right.$ disposable Endostitch ${ }^{\circledR}$ suturing device $^{8}$ ) in a double continuous (inverting non-perforating) Lembert suture, starting cranially (Fig 2). The suture material (glycolide lactide copolymer ${ }^{9}$ USP 2-0) consisted of a doublepointed needle with a suture attached in the centre. The needle was held securely in the jaws of the suture device. The suture device was positioned over one side of the bladder tear. A switch of the toggle lever and squeezing the handles of the device passed the needle smoothly through the bladder wall and the needle was picked up and locked by the contralateral side of the jaw. Then, the suture was pulled through the tissue and the device was positioned over the next location where the needle should pass the bladder wall. It was even possible to pass the needle at one moment through

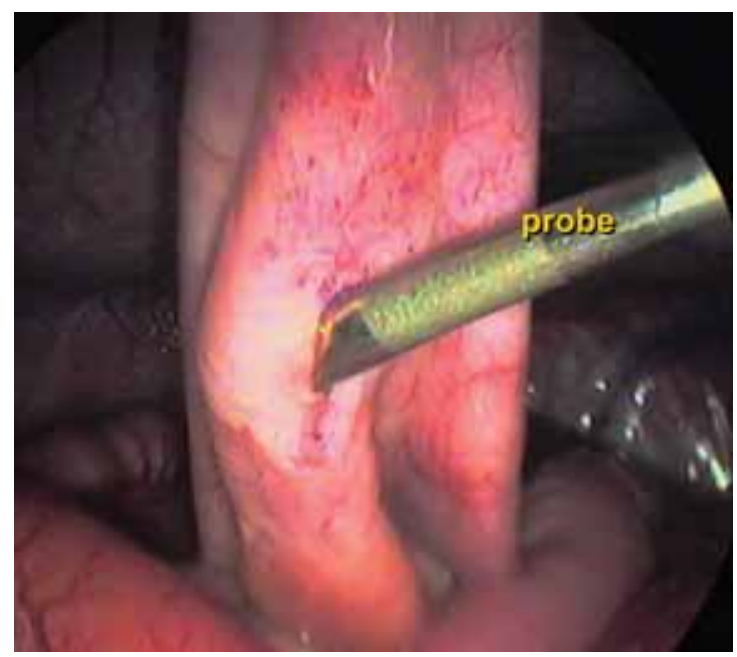

Fig 1b A probe is positioned in the defect.

Ein Taststab ist durch den defekt in die Blase eingeführt

both sides of the bladder tear. When necessary the bladder could be grasped with a Babcock or endoscopic atraumatic forceps ${ }^{5}$ to ensure the placement of the needle and prevent the placement of a perforating suture. The second layer was made starting caudally with the same material and the suture knot was made with the long tail of the suture starting point of the first layer. The final surgical knot was made extracorporally by removing the $12 \mathrm{~mm}$ instrumental trocar and positioning the cranial end of the bladder tear underneath the 
abdominal wall at the place of the incision. A watertight closure was confirmed by filling the bladder retrograde through a urethral catheter with $0,9 \% \mathrm{NaCl}(500 \mathrm{ml})$. The bladder was drained. Then the abdominal cavity was flushed with $0,9 \% \mathrm{NaCl}(3 \mathrm{~L})$ with the assistance of a suction lavage cannula ${ }^{5}$ attached to a suctionpump. The urethral catheter and instrumental trocars were removed, and the abdomen was deflated by the open laparoscopic trocar. The portal wounds were closed with simple interruptured sutures (external rectus sheath and skin) with poliglecaprone 2510 USP 2-0. Anaesthesia was stable and uneventful. None of the measured parameters exceeded the physiological limits, with the exception of $\mathrm{pH}$ (ranged: 7.09 to 7.18), $\mathrm{PaCO}_{2}$ (ranged: 56.5 to $69.6 \mathrm{mmHg}$ ) and Base Excess (BE, ranged: -8.8 to -11.5 $\mathrm{mmol} / \mathrm{L})$. Despite mechanical ventilation none of these values did improve during anaesthesia. Anaesthesia time was 130 minutes, and recovery was smooth.

\section{Postoperative management}

Wound healing was by primary intention and the foal urinated without difficulties. The first day after surgery the serum creatinine level had decreased to $90(\mathrm{~mol} / \mathrm{L}$ and ureum to 7 $\mathrm{mmol} / \mathrm{L}$. The leucocytes analysis revealed $8.4 \mathrm{G} / \mathrm{L}$. Venous $\mathrm{pH}, \mathrm{pCO}_{2}$ and $\mathrm{BE}$ were $7.38,43.5 \mathrm{mmHg}$ and +0.7 $\mathrm{mmol} / \mathrm{L}$, respectively.

After surgery sodium ampicillin (20 mg/kg BWT, iv, QID) was administered for 2 days. No postoperative wound swelling was noticed and the foal was discharged on the 2nd postoperative day and pasture exercise was advised.

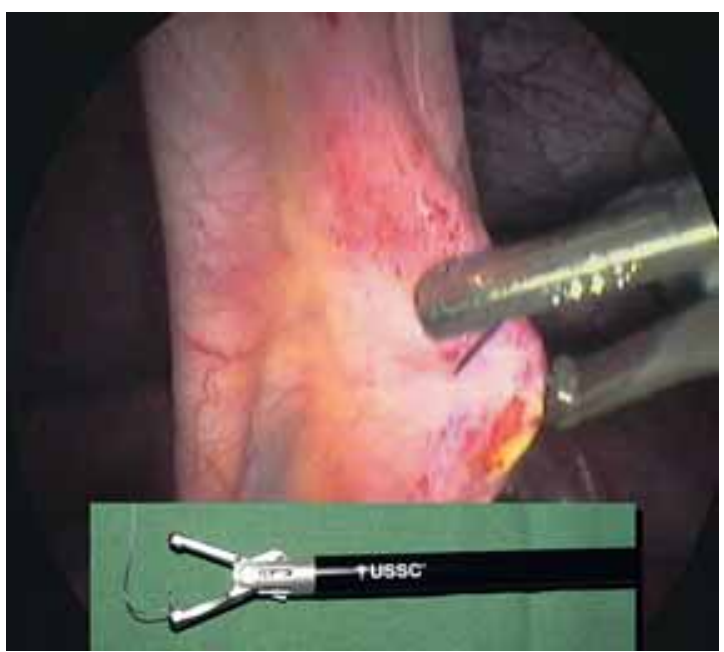

Fig 2 The endoscopic suturing device is positioned over the bladder defect, the jaws are released, the needle is in the left jaw of the device and the suture is pulled through the bladder wall. Inside the figure is a detail of the endoscopic device.

Das endoskopische Nähgerät ist über dem Balsendefekt positioniert, die Backen sind geöffnet, die Nadel liegt in der linken Backe des Geräts und der Faden wird durch die Blasenwand gezogen. Bildeinsatz: Das endoskopische Nähgerät.

Long-term follow-up

A follow-up telephone call one year after surgery revealed that the foal developed as expected and micturition problems were not noticed.
Case 2

History

A 7 day old Dutch Warmblood colt was admitted to the Department of Equine Sciences. The referring veterinarian diagnosed a distended abdomen without signs of pain or colic, and a prolaps of the rectum. The foal was uneventfully born out of a Standerdbred embryo-recipient mare. During the first 5 days of his life the foal did well. However, nobody was able to give information about the foal's micturition. Abdominocentesis showed a large quantity of clear fluid, possibly urine.

\section{Clinical findings}

On admission the foal was weak and lethargic, and was examined in lateral recumbency. The foal was tachypneic (60 breaths/minute), and tachycardic (120 beats/minute). Due to a rectum prolaps a temperature measurement was not done. The mucous membranes were pink and moist, however, slightly injected. A transabdominal ultrasound image showed free fluid, and the bladder could not be visualised. Laboratory results, again, were suggestive of a ruptured bladder with a hyponatremia (115 mmol/L), hypochloremia $(76 \mathrm{mmol} / \mathrm{L})$, and hyperkalemia $(6.8 \mathrm{mmol} / \mathrm{L})$. A leukocytosis $(16.5 \mathrm{G} / \mathrm{L})$ and a mild metabolic acidosis were noticed. Azotemia was present with a plasma creatinine concentration of 494 (mol/L and a blood urea nitrogen concentration of $29.8 \mathrm{mmol} / \mathrm{L}$. The clinician in charge opted to administer isosmotic intravenous fluids ( $\mathrm{NaCl} 0.9 \%$ ) to restore electrolyte balances. An abdominocentesis was performed and a large quantity of clear, light-yellow fluid was obtained. The creatinine concen-

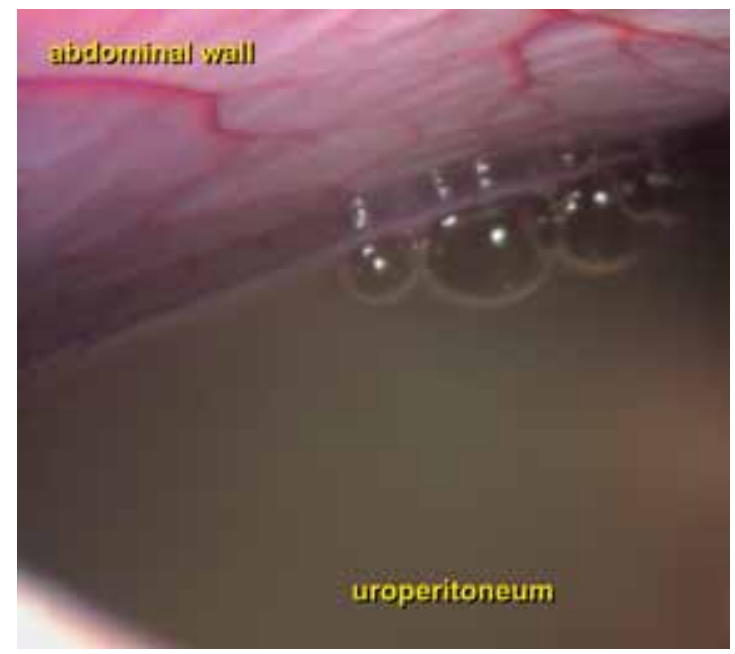

Fig 3a Laparoscopic view on the uroperitoneum.

Laparoskopische Ansicht des Uroperitoneums

tration in this fluid was 1116 (mol/L. The mare's udder appeared soft and poorly filled despite the fact that the foal stopped nursing her more than 12 hours ago.

\section{Surgical treatment}

The anaesthetic protocol for this case was similar to the first case, but no nalbuphine was given prior to induction. The foal was positioned in dorsal recumbency and routinely prepared for aseptic surgery. A 16-gauge French Foley catheter ${ }^{11}$ 
(length: $85 \mathrm{~cm}$ ) was passed through the urethra and secured in the bladder to permit intraoperative lavage of the bladder. The same procedure for making the laparoscopic portals was followed as described for the first case, although the $10 \mathrm{~mm}$ trocar sheath was directly placed in position. The distension of the abdomen was the same. The bladder rupture was located at the dorsocranial side, about $5 \mathrm{~cm}$ from the attachment

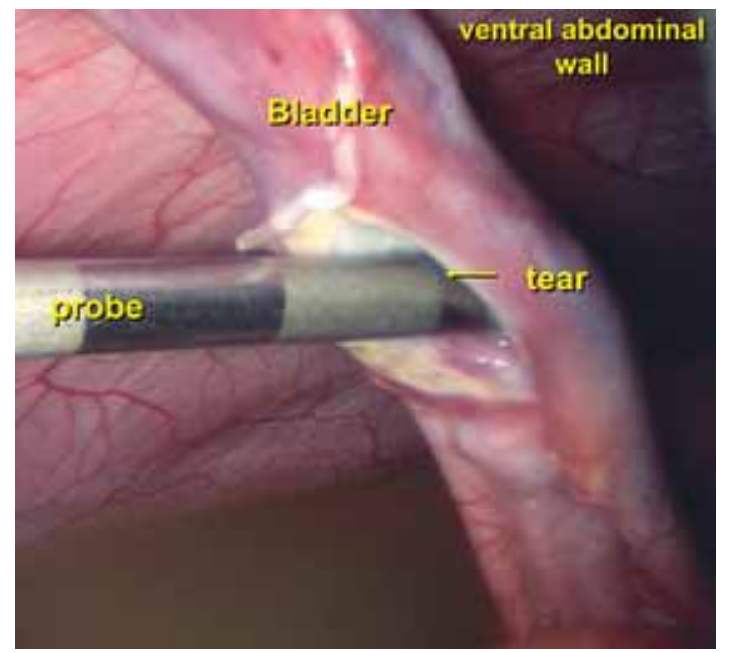

Fig 3b Case 2: Laparoscopic view of the bladder attached to the ventral abdominal wall. The defect is dorsocranially and the probe is positioned in the defect.

Fall 2: Laparoskopische Ansicht der mit der ventralen Bauchwand verklebten Blase.. Der Defelt liegt dorsocranial und der Taststab liegt im Defekt.

to the abdominal wall (Fig.3a and 3b). Three instrumental portals were placed: the first at the same level as the laparoscopic portal on the left side of the umbilicus (12 $\mathrm{mm}$ trocar) and the other two $5 \mathrm{~cm}$ caudal and lateral on both sides of the umbilicus (5 $\mathrm{mm}$ trocar). Peritoneal fluid was removed by introducing the suction lavage cannula, which was attached to a suctionpump, through one of the instrumental portals. The bladder wall was necrotic at the rupture edges and needed resection with endoscopic scissors ${ }^{2}$ until fresh healthy tissue became visible (Fig. 4). The necrotic tissue was removed through an instrumental portal. Again the foal was positioned in Trendelenburg position $\left(30^{\circ}\right.$ ) to obtain a better view on the bladder. The $10 \mathrm{~mm}$ endoscopic automatic suturing device was introduced through the $12 \mathrm{~mm}$ instrumental trocar left to the umbilicus. With a continuous Lembert suture layer (glycolide lactide copolymer USP 2-0), starting caudally, the bladder rupture was closed. Due to inexperience the suture tail was left too long, causing a delay in surgery time because the long tail had to be pulled through the tissue. The delay was also caused by a small intestinal loop that hung over the suture loop and had to be repositioned. Furthermore a knot in the suture was created which had to be unreleased laparoscopically. The instrumental portal on the right caudal side was used to pull the suture through the bladder wall with the assistance of an atraumatic grasping forceps. The final surgical knot was made as described in the previous case. The long tails of the suture were cut with the scissors. Then the bladder was filled with $3 / 4$ Liter $0.9 \% \mathrm{NaCl}$ via the Foley catheter to ensure that no leakage occurred. No leakage was present and the bladder was drained. Then the abdominal cavity was flushed as in the first case. The instruments were removed and the abdominal cavity was deflated through the open laparo- scopic trocar. The incisions were closed by simple interrupted sutures on the external rectus sheath (polyglactin 91012 USP 2-0) and on the skin (poliglecaprone10 USP 2-0).

Anaesthesia was stable and uneventful. In this case all measured parameters remained within physiological limits. Anaesthesia time was 190 minutes. Recovery was smooth.

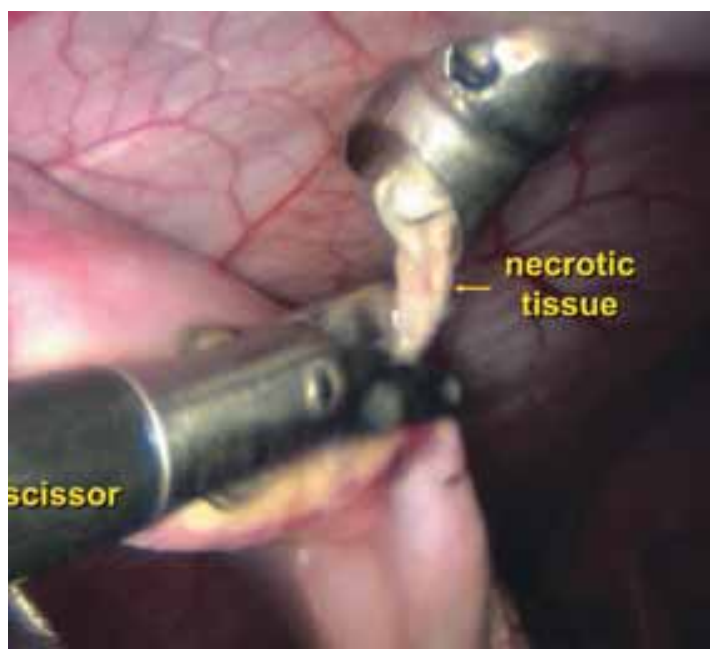

Fig 4 Laparoscopic view of the defect in the bladder of case 2. With endoscopic scissors the necrotic tissue is resected.

Laparoskopische Ansicht des Blasendefekts von fall 2. Mit einer endoskopischen Schere wird nekrotisches Gewebe reseziert

\section{Postoperative management}

Oral antibiotics (trimethoprim sulfadiazine $1325 \mathrm{mg} / \mathrm{kg}$ BWT) and non-steroidal anti-inflammatory drugs (vedaprofen $14^{\circledR}$ loading dose of $2 \mathrm{mg} / \mathrm{kg}$ BWT followed by twice daily doses of $1 \mathrm{mg} / \mathrm{kg}$ BWT) were administered for 3 days. The foal was confined together with the mare to a small box, with the Foley catheter left in the bladder to ensure proper bladder emptying. The foal experienced complications during the post-operative period. The foal stopped nursing the mare, and became more lethargic, while micturition was not noticed. Repeat transabdominal ultrasound examinations did not reveal free fluid in the abdomen, and a small volume of fluid within the bladder, which led to the conclusion that a decreased glomerular filtration rate (GFR) due to dehydration, rather than a leaking bladder into the abdomen was the reason for a decreased urine output. A leukocytosis developed (31 G/L), however, in the absence of azotemia. The foal was admitted to the intensive care unit and placed on a maintenance rate of intravenous fluids ( $4 \mathrm{ml} / \mathrm{kg} / \mathrm{hour}$ ). Additionally, the foal was fed once every hour by stomach tube with a mixture of mare's milk and a commercial milk replacer to achieve an enteral feeding volume of $15 \%$ of its body weight in liters, fed over a period of 24 hours. Treatment with trimethoprim-sulfadiazine (30 mg/kg BWT, po, BID) was continued, and, anti-ulcer therapy with an $\mathrm{H}_{2}$-blocking agent (cimetidine15: $15 \mathrm{mg} / \mathrm{kg}$ BWT, po, TID) in combination with a local protectant (sucralfate 16, $40 \mathrm{mg} / \mathrm{kg}$ BWT, po, TID) was initiated. The foal improved surprisingly quickly after initiation of therapy. Twenty-four hours post-intervention the foal was again able to nurse the mare, however, due to insufficient milk production of the mare the foal was bottle-fed in addition. Urine production, although not measured, improved during the 12 hours post-intervention period, and the Foley catheter was removed. 
Micturition appeared normal and well-coordinated. Leukocyte concentrations were normal $(8.3 \mathrm{G} / \mathrm{L})$ at the moment the foal showed signs of improvements.

\section{Discussion}

Excellent exposure and excess of the bladder was achieved in both cases. Laparoscopic techniques in bladder ruptures offers a better visualisation of the bladder (the dorsal and ventral part of the bladder as well as the urachus) and associated structures. With correct placement of the instrumental portals manipulation of the bladder can be performed very well. By using the Trendelenburg position the bladder becomes more exposed and less covered by intestines. The fact that the foals had not fastened prior to surgery did not influence the exposure of the bladder. Having in mind that both foals' dietary intake was their dam's milk respectively, and nutritional intake was diminished for several hours prior to surgery. Prior to inducing anaesthesia fluid losses and electrolyte imbalance were corrected, and slow decompression of the abdomen was performed in order to reduce the risk of cardiac dysrhythmias and hypovolaemic shock, to otherwise limit the risks of anaesthesia (Lillich and DeBowes 1999).

Concerning the anaesthetic procedure of young foals, preferably drugs with minimal influence on both respiratory and cardiovascular system are used. Especially foals suffering from uroperitoneum are high risk patients for general anaesthesia, despite preceding medical stabilization. Therefore, no sedative was administered for premedication and propofol and isoflurane were chosen for induction and maintenance, respectively. In our clinic ventilation of young foals under general anaesthesia is mostly mechanically supported. Moreover, with horses in Trendelenburg position and distension of the abdomen with $\mathrm{CO}_{2}$, like in these cases, mechanical ventilation is recommended (Peroni and Rondenay 2002). However, mechanical ventilation does not guarantee a normalized $\mathrm{PaCO}_{2}$ as demonstrated by case one.

Due to the umbilical remnants it is not possible to make the laparoscopic portal through the umbilicus. Care must be taken when introducing the trocars because of the thin abdominal wall and the relative shallow depth of the abdomen compared to adult horses (Fischer 1998).

Although the described laparoscopes can be used, shorter laparoscopes between 35 - $40 \mathrm{~cm}$ have sufficient length to perform surgery in young foals and are probably easier to manipulate. When using the longer laparoscopes it is advisable to make the laparoscope and the instrumental portal about $5 \mathrm{~cm}$ cranially of the umbilicus thus creating more working distance to the bladder for instance $10-15 \mathrm{~cm}$ cranial to the umbilicus as described for the resection of umbilical structures (Fischer 1998). Edwards et al. (1995) describes the use of the instrumental portals $8 \mathrm{~cm}$ cranial to the inguinal ring, but that foal was 90 days old and had a larger abdominal cavity.

Due to the fact that the bladder is connected to the umbilical structures by the urachus the bladder is held under tension 
which increases visibility. No risk of excessive traction on the urachus occurs compared to the conventional method of surgery, where exposure of the bladder is achieved by sustaining traction on the urachus. Also, there is no necessity of placing stay sutures for additional suppport and control of the bladder (Aver 1993). Wound debridement with the purpose of creating a fresh wound surface is possible by the use of laparoscopic scissors or might even be done with the use of a surgical knife.

In conventional surgery mostly the remnants of the umbilicus are removed (Lillich and DeBowes 1999). With the described technique there is no need to amputate the urachus, umbilical arteries and vein (unless they appear inflamed), thus creating a less traumatic surgical method.

Intracorporal suturing demands laparoscopic suture experience and is therefore time-consuming for the beginner (Brugmans and Deegen 2001). The use of the endoscopic suturing device (Endostich) has been described for the laparoscopic closure of the bladder as a part of assisted resection of infected umbilical structures in foals (Fischer 1998) as well as for laparoscopic bladder resection in healthy calves (Bouré et al 2001). It reduces surgery time, but care has to be taken to position the sutures in the right place to obtain an inverted Lembert suture and prevent intraluminal material (Eden 1996). In the described cases the used suture was too long due to inexperience, which increased surgery time. Intracorporal suture techniques with the use of 2 needle holders are less expensive, but demand technically experienced skills. Closure of the defect with the use of staples is technically easier, and might reduce surgery time, but has the risk of the formation of calculi (Edwards et al 1999). The use of two Endoloop sutures placed over the tear is described in human literature as a safe and simple method to suture small tears (Yin et al 1999). It has the disadvantage of an everting suture but is easily learned and needs no special laparoscopic suturing skills and might also be an option for foals (Poffenberger 1996).

Bladder tears in foals seem to occur infrequently $(0.2-2.5 \%$ of the newborn foals, Hackett 1984), and male foals are reportedly more often affected than females. The tear is thought to occur during parturition when increased pressure on the foal's abdomen may also cause an intravesical pressure high enough to cause rupture. The much longer urethra of a colt compared to the short urethra of a filly is thought to be the obstacle preventing urine to escape out of the bladder when increased pressure occurs (Fenger 1998, Hackett 1984, Richardson and Kohn 1983). Assuming that this is the pathogenesis of all bladder ruptures in foals the problems of anuria, oliguria, and/or distended abdomen should occur much earlier than in the 2 described cases. Also, the urine production in a newborn foal during the first 14 days of life is between 4 - $7 \mathrm{ml} / \mathrm{kg} /$ hour (Brewer 1993). Without scientific proof we are left with the impression that the tear in the two foals must have occurred at some point post-partum, and not periparturient. Further pathogenesis may include abdominal trauma at a later point of time, or dyssynergia, an uncoordinated contraction of the detrusor muscle in the bladder wall against a closed urethral sphincter, as described in hypoxic foals (Fenger 1998). Therefore we chose to leave the perioperatively placed Foley catheter in place for 36 hours until normal micturition had been observed. Whereas the first foal had been seen urinating actively after surgery the urethral catheter was removed directly after surgery. In foal 2 no active urination was noticed and dyssynergia was suspected. The catheter was left in place for 36 hours to be sure that the foal was able to urinate.

The postoperative problems of anorexia and leukocytosis seen in the second case may have been caused by the $\mathrm{CO}_{2}$ used to inflate the abdomen which is known to cause a transient chemical peritonitis (Rijkenhuizen 2002). Peritonitis due to the uroperitoneum is rare (Lillich and DeBowes 1999) and was not considered a problem in this case. No contamination of the incision with urine or bacteria resulting in incisional edema and drainage as described for conventional surgery was noticed (Lillich and DeBowes 1999). The relatively small incisions decreased the risk for such complications.

Laparoscopic approach of bladder ruptures in foals seems to be indicated based on the good visualisation of the bladder: the dorsal and ventral part of the bladder as well as the urachus, locations were the tears can be situated (Lillich and DeBowes 1999). Successful repair seems not to be limited by accessibility, whereas the bladder could be approached from all directions. Based on the described cases the laparoscopic approach of bladder ruptures seems to be a viable option to operate minimally invasive and has a short reconvalesence period, although the experience is admittedly limited. The main disadvantage is the longer duration of the operation. However with better experience in suturing techniques the surgical time will be shortened

\section{Manufacturers' addresses}

1 Ampi $2000{ }^{\circledR}$ p.i.(Aesculaap B.V., Boxtel, The Netherlands 2 Nubain ${ }^{\circledR}$ (Lamepro B.V., Raamsdonkveer, The Netherlands

3 Rapinovet $^{\circledR}$ (Schering-Plough Animal Health, Brussels, Bel gium

4 Isofluraan ${ }^{\circledR}$ (Pharmachemie B.V., Haarlem, The Netherlands 5 Storz GmbH\&Co. Tuttlingen, Germany.

6 Dr.Fritz Endoskopie \& Dokumentations-Systeme, Tuttlingen, Germany.

7 TriStar Surgical Trocar, Ethicon Endo-Surgery, Johnson \& Johnson, Amersfoort, The Netherlands.

8 Endostitch ${ }^{\circledR}$ suturing device Auto Suture Company

9 Polysorb ${ }^{\circledR}$ Endo-Stich 2-0 disposable loading Unit, Autosu ture Company

10 Monocryl ${ }^{\circledR}$, Johnson \& Johnson, Amersfoort, The Nether lands

11 Cook Vetin Aacofarma, Boxtel, The Netherlands

12 Vicryl ${ }^{\circledR}$, Johnson \& Johnson, Amersfoort, The Netherlands

13 Sultrisan ${ }^{\circledR}$ Orale Pasta, Anisane Pet Health Products, Raamsdonksveer, The Netherlands.

14 Quadrisol $^{\circledR}$, Intervet International B.V., Boxmeer, the Netherlands.

15 Cimetidine, Apotheek Faculteit Diergeneeskunde, Utrecht, The Netherlands

16 Ulcogant $^{\circledR}$, E. Merck Nederland B.V., Amsterdam, The Netherlands 


\section{Literature}

Appeltans B M, Schapmans S, Willemsen P J, Verbruggen P J, Denis L J (1998): Urinary bladder rupture: laparoscopic repair. Br J Urol. 81, 764-765

Baerveldt M C und Klein W R (1991): Rupture of the bladder and of the urachus in foals. A literature review. Tijdschr Diergeneeskd. $116,221-228$

Booth T M, Howes D A und Edwards G B (2000): Bethanecholresponsive bladder atony in a colt foal after cystorrhaphy for cystorrhexis. Vet Rec 147, 306-308

Brewer B (1990): The urogenital system. In: Equine Clinical Neonatology. Koterba A M, Drummond W H und Kosch P C (eds) Lea\&Feabiger, Philadelphia, 443-496

Cottam D, Gorecki P J, Curvelo M, Shaftan G W (2001): Laparoscopic repair of traumatic perforation of the urinary bladder. Surg Endosc. 15, 1488-1489

Edwards R B 3rd, Ducharme N G und Hackett R P (1995): Laparoscopic repair of a bladder rupture in a foal. Vet Surg. 24, 60-3

Fenger CK (1998): Diseases of foals: neonatal and perinatal diseases, In: Equine Internal Medicine, eds: Reed S M and Bayly W M, WB Saunders Company, Philadelphia, 964-965

Fischer A T (1999): Laparoscopically assisted resection of umbilical structures in foals. J Am Vet Med Assoc. 214, 813-816, 17911792

Hackett R P (1984): Rupture of the urinary bladder in neonatal foals. Comp Cont Educ Pract Vet 6, 488-494
Hughes-Ellis T (2000): Bladder atony in a colt foal after cystorrhaphy for cystorrhexis. Vet Rec. 147, 556

Lillich and DeBowes (1999) Bladder. In Equine Surgery. Ed. J. A. Aver and J.A.Stick. Philadelphia, W.B.Saunders. 596-610

Peroni J F and Rondenay Y (2002): Analgesia and anesthesia for equine laparoscopy and thoracoscopy. In Equine Diagnostic and Surgical Laparoscopy. Ed. A.T. Fischer jr., W.B. Saunders Company, Philadelphia. 119-127

Poffenberger R J (1996): Laparoscopic repair of intraperitoneal bladder injury: a simple new technique. Urology. 47, 248-249

Richardson D W and Kohn CW (1983): Uroperitoneum in the foal. J Am Vet Med Assoc. 182, 267-271

Tay K P, Ravintharan T, Lim P H und Chng H C (1995): Emergency laparoscopic repair of spontaneous and traumatic bladder rupture. Br J Urol. 75, 550-551

Yin C S, Li Y T, Chao T C and Yu MS (1999:) Laparoscopic loop ligatures for bladder repair during laparoscopic surgery. Int J Gynaecol Obstet. 66. 47-49

Astrid B. M. Rijkenhuizen, DVM, PhD, Dipl. ECVS

Department of Equine Sciences, Division of Equine Surgery

Faculty of Veterinary Medicine, Utrecht University

Yalelaan 12, NL-3584 CM, Utrecht

email: a.rijkenhuizen@vet.uu.nl 